\title{
Inheritance in OCD in Moslems
}

\section{Nahla $\mathbf{N}^{1 *}$, Nader $\mathrm{D}^{2}$, Mona $\mathbf{R}^{3}$ and Mahmoud $\mathrm{E}^{2}$}

${ }^{1}$ Professor of Psychiatry, Neuropsychiatry Department, Ain Shams University, Cairo, Egypt

${ }^{2}$ Associate Professor of Psychiatry, Neuropsychiatry Department, Ain Shams University, Cairo, Egypt

${ }^{3}$ Professor of Psychiatry, Institute of Childhood Studies, Ain Shams University, Cairo, Egypt

\begin{abstract}
There is increasing evidence that obsessive-compulsive disorder (OCD) is mediated by genetic factors. Although the precise mechanism of inheritance is unclear, recent evidence has pointed towards the involvement of the serotonergic and dopaminergic systems in the disorder's development.

Objectives: To examine the clinical profile of symptoms in obsessive compulsive patients and their first and second degree relatives.

Subjects and Methods: This study was designed in the Institute of psychiatry, Ain Shams University Hospitals. After signing an informed consent form, all the subjects 23 patients and 19 relatives were diagnosed according to DSM-IV and Structured Clinical Interview for DSM-IV (SCID I) and General Health Questionaire for psychiatric morbidity. Severity of OCD symptoms was assessed using Yale-Brown Obsessive Compulsive Scale (Y-BOCS) Symptom analysis was done on four symptom factor levels and presenting symptoms.
\end{abstract}

Results: Showed 15 OCD patients had positive family history of psychiatric illness. 19 of their relatives showed 11 had OCD, 6 had psychosis and 3 had depression. The most prevalent symptom in OCD patients and their relatives was washing compulsions and religious obsessions.

Conclusion: Genetic factors account for most of OCD symptoms in patients diagnosed with the disorder. Environmental factors also play a role in how these symptoms are expressed by observational learning.

Keywords: Psychiatry; Obsessive; Serotonin; Dopaminergic; Oligodendrocytes

\section{Introduction}

Obsessive-Compulsive Disorder (OCD) is characterized by the presence of either obsessions or compulsions that cause Significant Distress to Afflicted individuals.

Estimates of prevalence vary slightly across countries and symptom presentation depends on cultural and religious factors. Genetic factors account for $45-65 \%$ of OCD symptoms in patients diagnosed with the disorder. Environmental factors also Play Arolein How These Anxiety Symptoms Are expressed [1].

Researchers found that relatives with the disorder possessed a difference in a gene called, SLC1A1, which is the glutamate transporter gene. They found that the discrepancy in the gene caused the flow of glutamine, in relation to brain cells, to happen much quicker for people with the disorder [2-4]. The researchers at Yale and the National Institute of Mental Health (NIMH) have found a mutation in the gene coding of the human serotonin transporter (sSERT). Serotonin is a neurotransmitter that helps transmit signals across nerve cells to help process information. Serotonin usually travels back after the signal transports but some people do not receive enough serotonin back. This lack of serotonin reuptake can increase the risk of someone having OCD [2-4].

Early-onset OCD appears to be a subtype that exhibits distinct clinical features and that is associated with greater familial loading and clinical data revealed an association between early age of onset and an increased frequency of tics, Tourette's disorder, and trichotillomania (TTM). The genetic studies yielded statistically significant results when the allelic distributions of genetic variants in the dopamine receptor type 4 gene (DRD4) were analyzed. These data support a role for the dopaminergic system, which may be relevant to the development of early-onset OCD [5]. People with OCD shows increased grey matter volumes in bilateral lenticular nuclei, extending to the caudate nuclei, while decreased grey matter volumes in bilateral dorsal medial frontal/anterior cingulate gyri with dopaminergic hyper function in the prefrontal cortex and serotonergic hypo function in the basal ganglia [6].

\section{Subjects and Methods}

23 cases were randomly selected from OCD patients attending the outpatient clinics. They were suffering from OCD according to the DSM-IV diagnostic criteria for research. Patients with other evident neurological disorder or substance Abuse were excluded.

Of first and second degree relatives of OCD Probands of this study, those with history of psychiatric disorders were included, leaving 19 affected relatives. They included parents, siblings and offspring of the patients. All subjects were included in the study after signing an informed written consent.

All subjects were examined using General Health Questionnaire for screening of psychiatric morbidity and Structured Clinical Interview for DSM-IV for diagnosis. Symptom analysis was done on two levels 1) Symptom Factor and 2) presenting OCD symptoms. The 4 OCD factors

*Corresponding author: Nahla N, Neuropsychiatry Department, Ain Shams University, Egypt, Tel: +20 2 26831474; E-mail: nahlanagy64@yahoo.com

Received November 02, 2015; Accepted November 09, 2015; Published December 30, 2015

Citation: Nahla N, Nader D, Mona R, Mahmoud E (2015) Inheritance in OCD in Moslems. J Ment Disord Treat 1: 103. doi:10.4172/2471-271X.1000103

Copyright: $\odot 2015$ Nahla N, et al. This is an open-access article distributed under the terms of the Creative Commons Attribution License, which permits unrestricted use, distribution, and reproduction in any medium, provided the original author and source are credited. 
were (1) symmetry factor, which contained symmetry obsessions and ordering, repeating, and counting compulsions; (2) forbidden thoughts factor, which contained aggression and sexual and religious obsessions; (3) cleaning factor, which contained contamination obsessions and cleaning compulsions; and (4) hoarding factor, which contained hoarding obsessions and compulsions [7]. Most common symptoms of obsessive-compulsive disorder.

\section{Obsessions}

Fear of causing harm to someone else

Fear of harm coming to self

Fear of contamination

Need for symmetry or exactness

Sexual and religious obsessions

Fear of behaving unacceptably

Fear of making a mistake

Compulsions

Cleaning

Hand washing

Checking

Ordering and arranging

Hoarding

Asking for reassurance

Mental acts

Counting

Repeating words silently

Ruminations Neutralising thoughts [8].

Psychiatric comorbidity was examined in both patients and relatives.

Results were analysed as percentages means and standard deviations. Quantitative values were compared using $\mathrm{T}$.

\section{Discussion}

In this study we found $15(65.22 \%)$ out of 23 OCD patients had positive family history for psychiatric disorder. 11(47.83\%) relatives had OCD which points to high genetic loading and severity of symptoms according to Y-BOCS 16 (69.57\%).6 (31.58\%) of affected relatives showed psychotic symptoms according to SCID I (delusions of reference and persecution while 3 (15.79\%) showed major depression.

These data goes with research studies that support a role for the dopaminergic and serotonergic systems, which may be relevant to the development of early-onset OCD [5,6]. Imaging studies show dopaminergic hyperfunction in the prefrontal cortex and serotonergic hypofunction in the basal ganglia which can help explanation of comorbid psychosis and depression in relatives of OCD patients.

Patients with a diagnosis of obsessive-compulsive disorder were examined in a longitudinal study with mean length of follow-up from onset to 47 years.

Results showed improvement in $83 \%$, including recovery in $48 \%$ (complete recovery, 20\%; recovery with subclinical symptoms, 28\%). Forty-eight percent had obsessive-compulsive disorder for more than 30 years. Early age of onset, having both obsessive and compulsive symptoms, low social functioning at baseline, and a chronic course were correlated with a worse outcome. Magical obsessions and compulsive rituals were correlated with a worse course. Qualitative symptom changes within the obsessive-compulsive disorder occurred in $58 \%$ of the patients [9].

The medial frontal cortex (MFC), including the dorsal anterior cingulate and the supplementary motor area, is critical for adaptive and inhibitory control of behavior. Abnormally high MFC activity has been a consistent finding in functional neuroimaging studies of obsessivecompulsive disorder. Compared with controls, OCD patients had greater relative activation of the supplementary motor area and deactivation of the rostral anterior cingulate.

Patients with OCD also showed reduced levels of neuronal $\mathrm{N}$-acetylaspartate in the dorsal anterior cingulate region, which was negatively correlated with their blood oxygen level-dependent activation of the region. This relationship may partly explain the nature of inhibitory control deficits that are frequently seen in this group of patients [10].

$\mathrm{N}$-acetylaspartate is a metabolite produced in neuronal mitochondria and is thought to reflect neuronal density and functional viability. It remains unclear whether reduced levels reflect neuronal loss or a state of (potentially reversible) neuronal dysfunction [11]. After its release from neurons, NAA is taken up and hydrolyzed by oligodendrocytes to act as a source of acetyl groups in a variety of metabolic processes, including myelin synthesis, lipid repair/fatty acid synthesis, osmotic regulation, and anti-inflammatory action. Reduced dAC NAA levels may, thus, reflect a variety of underlying metabolic and biochemical changes that, when considered in the context of the present findings, suggest that OCD patients have fewer healthy neurons in the region, necessitating the recruitment of adjacent and other task-related brain regions (e.g., the SMA, the lateral premotor, and the superior parietal) to perform at levels comparable with controls [12-17].

Planning is the ability to achieve a goal through a series of intermediate steps, such as plan generation, working memory, and internal evaluation and reward.

Imaging studies agree on the involvement of dorsolateral prefrontal cortex (DLPFC) and parietal-occipital regions during planning [18-30].

During planning, decreased frontal-striatal responsiveness was found in OCD patients, mainly in dorsolateral prefrontal cortex and caudate nucleus. In addition, OCD patients showed increased, presumably compensatory, involvement of brain areas known to play a role in performance monitoring and short-term memory processing, such as anterior cingulate, ventrolateral prefrontal, and parahippocampal cortices [31].

Recent neuropsychological studies have shown cognitive impairments in OCD, particularly with regard to visuospatial processing, executive functioning, and motor speed $[32,33]$.

In this study we found the most prevalent symptom with high familial loading is washing related to religious issues (before praying and after menstruation for moslem OCD patients.

A recent meta-analysis of 21 factor-analysis studies involving $>5000$ subjects demonstrated a fairly robust 4 -factor structure for OCD that 
was remarkably consistent across the lifespan (7). The 4 OCD factors were (1) symmetry factor, which contained symmetry obsessions and ordering, repeating, and counting compulsions; (2) forbidden thoughts factor, which contained aggression and sexual and religious obsessions; (3) cleaning factor, which contained contamination obsessions and cleaning compulsions; and (4) hoarding factor, which contained hoarding obsessions and compulsions. These OCD symptom dimensions have been associated with distinct patterns of comorbid psychiatric conditions, different patterns of heritability, and specific genetic polymorphisms, as well as distinct symptom-associated patterns of neural activity, as measured with functional MRI [34-37]. Symptom dimensions have been associated with different responses to pharmacologic and non-pharmacologic treatments $[38,39]$.

Different obsessive-compulsive symptom dimensions are mediated by relatively distinct components of frontostriatothalamic circuits. OCD Patients demonstrated significantly greater activation than controls in bilateral ventromedial prefrontal regions and right caudate nucleus (washing); putamen/globus pallidus, thalamus, and dorsal cortical areas (checking); left precentral gyrus and right orbitofrontal cortex (hoarding) [34].

In our study OCD patients showed co-morbid psychiatric illnesses as major depression (21.75\%), anorexia nervosa (13.04\%), trichotillomania (8.7\%) and tourette syndrome (4.35\%) [40].

\section{References}

1. Jonathan A, Dean M (2009) Obsessive-compulsive disorder. The Lancet 374 : 491-499.

2. Brady P (2008) Genetics may help explain OCD. Retrieved September 16 , from Yale Daily News.

3. Nauert R (2008) Genetic Link for OCD Discovered. Retrieved September 16 from Psychcentral.com.

4. (2008) The Numbers Count: Mental Disorders in America. National Institute of Mental, USA.

5. Comings DE, Comings BG (1987) Hereditary agoraphobia and obsessivecompulsive behaviour in relatives of patients with Gilles de la Tourette's syndrome. The British Journal of Psychiatry151: 195-199.

6. Joaquim R, Odile HA, Simon S, David M (2010) Meta-analytical comparison of voxel-based morphometry studies in obsessive-compulsive disorder vs other anxiety disorders. Archives of General Psychiatry 67: 701-711.

7. Bloch MH, Landeros WA, Rosario MC, Pittenger C, Leckman JF (2008) Metaanalysis of the symptom structure of obsessive-compulsive disorder. Am J Psychiatry165: 1532-1542

8. Heyman, Mataix CD, Fineberg NA (2006) Obsessive-compulsive disorder. BMJ 333: 424-429.

9. Skoog G, Skoog IA (1999) 40-Year Follow-up of Patients With Obsessivecompulsive Disorder. Arch Gen Psychiatry 56: 121-127.

10. Yucel M, Harrison BJ, Wood SJ, Fornito A, Wellard RM, et al. (2007) Functional and Biochemical Alterations of the Medial Frontal Cortex in ObsessiveCompulsive Disorder. Arch Gen Psychiatry 64: 946-955.

11. Barker PB (2001) N-acetyl aspartate: a neuronal marker? Ann Neurol 49: 423-424.

12. Baslow $\mathrm{MH}(2003) \mathrm{N}$-acetylaspartate in the vertebrate brain: metabolism and function. Neurochem Res 28: 941-953.

13. Baslow MH, Suckow RF, Sapirstein V, Hungund BL (1999) Expression of aspartoacylase activity in cultured rat macroglial cells is limited to oligodendrocytes. J Mol Neurosci 13: 47-53.

14. Tallan $\mathrm{HH}$ (1957) Studies on the distribution of $\mathrm{N}$-acetyl-L-aspartic acid in brain. J Biol Chem 224: 41-45.

15. D'Adamo AF, Gidez LI, Yatsu FM (1968) Acetyl transport mechanisms: involvement of $\mathrm{N}$-acetyl aspartic acid in de novo fatty acid biosynthesis in the developing rat brain. Exp Brain Res 5: 267-273.
16. Sager TN, Fink JA, Hansen AJ (1997) Transient elevation of interstitia $\mathrm{N}$-acetylaspartate in reversible global brain ischemia. J Neurochem 68: 675682.

17. Rael LT, Thomas GW, Bar-Or R, Craun ML, Bar-Or D (2004) An antiinflammatory role for $\mathrm{N}$-acetyl aspartate in stimulated human astroglial cells. Biochem Biophys Res Commun 319: 847-853

18. Owen AM, Doyon J, Petrides M, Evans AC (1996) Planning and spatial working memory: a positron emission tomography study in humans. Eur J Neurosci: 353-364.

19. Baker SC, Rogers RD, Owen AM, Frith CD, Dolan RJ, et al. (1996) Neura systems engaged by planning: a PET study of the Tower of London task. Neuropsychologia 34: 515-526.

20. Dagher A, Owen AM, Boecker H, Brooks DJ (1999) Mapping the network fo planning: A correlational PET activation study with the Tower of London task. Brain 122: 1973-1987.

21. Rowe JB, Owen AM, Johnsrude IS, Passingham RE (2001) Imaging the mental components of a planning task. Neuropsychologia 39: 315-327.

22. Schall U, Johnston P, Lagopoulos J, Juptner M, Jentzen W, et al. (2003) Functional brain maps of Tower of London performance: a positron emission tomography and functional magnetic resonance imaging study. Neuroimage 20: $1154-1161$.

23. Morris RG, Ahmed S, Syed GM, Toone BK (1993) Neural correlates of planning ability: frontal lobe activation during the Tower of London test. Neuropsychologia 31: 1367-1378.

24. Rezai K, Andreasen NC, Alliger R, Cohen G, Swayze V (1993) The Neuropsychology of the Prefrontal cortex. Arch Neurol 50: 636-642.

25. Lazeron RH, Rombouts SA, Machielsen WC, Scheltens P, Witter MP (2000) Visualizing brain activation during planning: the Tower of London test adapted for functional MR imaging. AJNR Am J Neuroradiol 21: 1407-1414.

26. Fincham JM, Carter CS, Van VV, Stenger VA, Anderson JR (2002) Neura mechanisms of planning: a computational analysis using event-related fMRI. Proc Natl Acad Sci USA 99: 3346-3351.

27. Vanden HOA, Groenewegen HJ, Barkhof F, Lazeron RHC, Van DR, et al (2003) Frontostriatal system in planning complexity: a parametric functional magnetic resonance version of the Tower of London task. Neuroimage 18: 367-374.

28. Newman SD, Carpenter PA, Varma S, Just MA (2003) Frontal and parieta participation in problem solving in the Tower of London: fMRI and computational modeling of planning and high-level perception. Neuropsychologia 41: 16681682.

29. Cazalis F, Valabreque R, Pelegrini IM, Asloun S, Robbins TW, et al. (2003) Individual differences in prefrontal cortical activation on the Tower of London planning task: implication for effortful processing. Eur J Neurosci 17: 22192225.

30. Beauchamp MH, Dagher A, Aston J, Doyon J (2003) Dynamic functiona changes associated with cognitive skill learning of an adapted version of the Tower of London task. Neuroimage 20: 1649-1660.

31. Heuvel VOA, Veltman DJ, Groenewegen HJ, Cath DC, van Balkom AJ, et al (2005) Frontal-Striatal Dysfunction During Planning in Obsessive-Compulsive Disorder. Arch Gen Psychiatry 62: 301-309

32. Purcell R, Maruff $P$, Kyrios $M$, Pantelis $C$ (1998) Cognitive deficits in obsessivecompulsive disorder on tests of frontal-striatal function. Biol Psychiatry 43: 348357.

33. Greisberg S, McKay D (2003) Neuropsychology of obsessive-compulsive disorder: a review and treatment implications. Clin Psychol Rev 23: 95-117.

34. Mataix-Cols D, Wooderson S, Lawrence N, Brammer MJ, Speckens A, et al (2004) Distinct neural correlates of washing, checking, and hoarding symptom dimensions in obsessive-compulsive disorder. Arch Gen Psychiatry 61: 564-576.

35. Hasler G, Kazuba D, Murphy DL (2006) Factor analysis of obsessivecompulsive disorder YBOCS-SC symptoms and association with 5-HTTLPR SERT polymorphism. Am J Med Genet B Neuropsychiatr Genet 141: 403-408

36. Hasler G, LaSalle RVH, Ronquillo JG, Crawley SA, Cochran LW, et al (2005) Obsessive-compulsive disorder symptom dimensions show specific relationships to psychiatric comorbidity. Psychiatry Res 135: 121-132. 
37. Mataix CD, Rosario CMC, Leckman JF (2005) A Multidimensional Model of obsessive-compulsive disorder. Am J Psychiatry 162: 228-238.

38. Mataix CD, Rauch SL, Manzo PA, Jenike MA, Baer L (1999) Use of factoranalyzed symptom dimensions to predict outcome with serotonin reuptake inhibitors and placebo in the treatment of obsessive-compulsive disorder. Am J Psychiatry 156: 1409-1416
39. Mataix CD, Marks IM, Greist JH, Kobak KA, Baer L (2002) Obsessivecompulsive symptom dimensions as Predictors of compliance with and response to behaviour therapy: Results from a controlled trial. Psychother Psychosom 71: 255-262

40. Piggott TA, Heureux LF, Dubbert B, Bernstein S, Murphy DL (1994) Obsessive compulsive disorder: comorbid conditions. J Clin Psychiatry 55: 15-27. 